T. Hughes: Professor Lliboutry has postulated a substantial temperate ice layer above the bed for parts of the Antarctic ice sheet. What modifications, in wave length, power, etc. of your system would you recommend to get good internal and basal reflections in cases where a cold layer overlies a temperate ice layer, both of substantial thickness?

WATTS: If other radio-echo sounding systems are capable of obtaining good reflections, you should stick with them. Our system should be able to penetrate fairly deep polar ice, but if the temperate layer is deep, the power may have to be increased. Frequencies of $\mathrm{I}$ to $5 \mathrm{MHz}$ should still be adequate.

\title{
REFERENCE
}

Smith, B. M. E., and Evans, S. 1972. Radio echo sounding: absorption and scattering by water inclusion and ice lenses. Fournal of Glaciology, Vol. i 1, No. 61, p. 133-46.

\section{THE STUDY OF FRESH-WATER LAKE ICE USING MULTIPLEXED IMAGING RADAR}

\author{
By M. Leonard Bryan and R. W. Larson \\ (Radar \& Optics Division, Environmental Research Institute of Michigan, P.O. Box 6r8, \\ Ann Arbor, Michigan 48107 , U.S.A.)
}

Abstract. The study of ice in the upper Great Lakes, both from the operational and the scientific points of view, is receiving continued attention. Both quantitative and qualitative field work is being conducted to provide the needed background for accurate interpretation of remotely sensed data. The sensor data under discussion in this paper were obtained by a side-looking multiplexed airborne radar (SLAR). These were supplemented with groundtruth data.

Radar, due to its ability to penetrate adverse weather, is an especially important instrument for monitoring ice in the upper Great Lakes. It has been previously shown that imaging radars can provide maps of ice cover in these areas. However, questions concerning both the nature of the surfaces reflecting radar energy and the interpretation of the radar imagery continually arise.

Our analysis of ice in Whitefish Bay (Lake Superior) indicated that the combination of the ice/water interface with the ice/air interface is the major contributor to the radar backscatter as seen on the imagery. The ice has a very low dielectric constant $(<3.0)$ and a low loss tangent. Thus, this ice is somewhat transparent to the energy used by the imaging SLAR system. The ice types studied include newly formed black ice, pancake ice, and frozen and consolidated pack and brash ice.

Although ice thickness cannot be measured directly from the received signals, it is suspected that by combining the radar backscatter information with both meteorological and sea-state history of the area and with some basic ground truth, better estimates of the ice thickness may be provided. In addition, certain ice features (e.g. ridges, ice foots, areas of brash ice) may be identified with reasonable confidence. There is a continued need for additional ground work to verify the validity of imaging radars for these types of interpretations.

This paper is being published in full in another issue of the fournal of Glaciology. 